\title{
Dietary influences on cognitive development and behaviour in children
}

\author{
Jim Stevenson \\ Developmental Brain Behaviour Unit, School of Psychology, University of Southampton, Southampton SO17 1BJ, UK
}

\begin{abstract}
There are a number of ways in which food can influence behaviour, including malnutrition, types of diet, eating habits, pharmacological effects, food allergy, fatty acid deficiency and possibly food additives. The range of behaviour affected is also wide, and includes attention, conduct disorder and mood. A particular focus of interest has been the effects of food on hyperactivity in children. There is some initial evidence that fatty acids may influence hyperactivity in children with specific learning disabilities. The findings also suggest that some food additives (colourings, flavourings and preservatives) may increase hyperactivity in children with behaviour problems. For children showing behaviour problems such as hyperactivity the use of dietary manipulation tends to be a more acceptable approach to treatment than the use of drugs. However, there needs to be awareness of the dangers of the use of unsupervised restriction diets with children, and the use of dietary treatments alone is not likely to be sufficient treatment for many children with attention-deficit hyperactivity disorder. A study is currently underway to investigate the possible effects of additives on behaviour in the general population of children.
\end{abstract}

\section{Diet: Hyperactivity: Food additives: Children}

\section{Dietary influences on cognitive development and behaviour in children}

There are number of different ways in which food might affect the behaviour and development of children. In the present brief review illustrations will be given of the ways in which studies have demonstrated the role of particular aspects of diet in influencing cognition and behaviour. A recurrent theme will be the extent to which these effects are shown across the general population or are restricted to particular vulnerable subgroups.

\section{Malnutrition}

There is clearly a devastating effect of severe malnutrition on the development and growth of children. At the extreme this condition can result in severe threats to health, increased vulnerability to infection and indeed death. In relation to the topic of the present review the most relevant question is whether experiencing periods of severe malnutrition has enduring effects on behaviour and cognitive ability. A study undertaken in Peru (Berkman et al. 2002) has identified that stunting during the second year of life is associated with a ten-point lowering of the intelligence quotient score at age 9 years. These effects remain when other associated risk factors such as parasitic infections are controlled.

Although stunting is associated with cognitive and educational deficits later in childhood, there is increasing evidence that early intervention can reverse some of this effect. A study in the West Indies (Walker et al. 2005) has shown that although nutritional supplementation has no long-term effect on later cognitive development, the provision of psychosocial stimulation between the ages of 9 and 24 months is associated with improved scores on eleven of twelve cognitive and educational tests when the children are aged 17-18 years. In this same study the effects of stunting on behavioural development in children were investigated. This aspect has been less widely explored than cognitive development. It was found that, regardless of the social background of the children, those that are stunted during the early years are more likely to show conduct difficulties at home and educational attainment is also poorer than that for non-stunted children (Chang et al. 2002).

\section{Types of diet}

There have been relatively few studies that have looked specifically at variations in dietary content and its 
relationship to behavioural development in children. In their review Gibson \& Green (2002) have shown that, in general, nutritional composition does show a tendency to be related to mood and cognitive differences, although the data are rather inconsistent. On an acute basis, a carbohydrate-rich but protein-poor meal can have a sedative and anxiolytic effect. Protein-rich meals may improve reaction time and be generally arousing but at the same time may increase unfocused vigilance. Again, on an acute basis fat-rich meals can lead to a decline in alertness especially where they differ from habitual fat intake. Protein-rich diets as opposed to meals have been associated with a decrease in positive and an increase in negative affect relative to carbohydrate-rich diets.

\section{Eating habits}

There has been much recent concern about the eating habits of children and how they may be affecting their behaviour and performance at school. The research evidence on their effects is somewhat inconclusive, but one area where an extensive range of studies have been undertaken is in relation to the importance of breakfast for school performance. This evidence has been reviewed by Bellisle (2004), who concludes that although the effects are not consistently shown for children who are generally wellnourished, the failure to take breakfast has a deleterious effect on the cognitive performance of children who are generally malnourished. For example, in an experimental study of the effects of glucose as a replacement for breakfast (Morris \& Sarll, 2001) eighty adolescents missed breakfast and then completed a listening comprehension task. Half the group were then given a drink containing glucose while the other half received a saccharin drink that was matched for taste, and the comprehension test was completed again. The results suggest that the negative effects of missing breakfast can be reversed by a glucose snack or drink taken early in the school day.

\section{Pharmacological effects}

Certain foods contain pharmacologically-active ingredients that can affect behaviour in all individuals (for a brief review of some of these effects, see Warner et al. 2003). The most obvious example of such an effect is that of caffeine on the central nervous system, which produces wakefulness and improves concentration. Chocolate has also been claimed to be a food containing pharmacologically-active substances, which include vaso-active amines such as histamine, tryptophan and serotonin. These amines are known to affect behaviour and mood if administered to individuals in high concentration. Last, alcohol in large quantities can have a substantive deleterious effect of cognition and behaviour. This effect is of concern in children, not least because regular consumption of psychoactive substances such as alcohol is associated with psychiatric morbidity. For example, a recent survey by Boys et al. (2003) of a sample of adolescents from England, Scotland and Wales aged 13-15 years has shown that there is a strong link between substance use, such as drinking alcohol and cannabis use, and psychiatric disorders. These effects are also strongly influenced by their common association with smoking.

\section{Food allergy}

There are a number of ways in which the adverse reactions to food could be linked to behavioural and cognitive difficulties in children. It is possible that there is a common causal mechanism whereby the factors promoting allergic disease also have an impact on central nervous system functioning. It is also possible that behavioural changes may arise as a secondary consequence of adverse reactions to food, and finally psychological factors might exacerbate allergic symptomatology. These mechanisms have been reviewed by Warner et al. (2003).

\section{Studies on food and hyperactivity}

Hyperactivity is a behavioural style characterised by overactivity, inattention and impulsivity. It shows marked variations across the range of severity in a general population of children. The distribution appears to be approximately normal, with some children showing rather little hyperactivity and others a considerable amount. Those children at the high end of this distribution may meet the diagnostic criteria for attention-deficit hyperactivity disorder (ADHD).

It is thought that variation on this continuum of hyperactivity and the risk of ADHD are primarily associated with a deficiency in dopamine (Sonuga-Barke, 2003). This dopamine hypothesis was developed in part as a consequence of the observation that stimulant drugs such as methylphenidate (Ritalin) bind to the dopamine transporter protein and inhibit reuptake of dopamine. These drugs can have a beneficial effect in reducing the hyperactivity shown by children. A second action of these drugs is to stimulate dopamine release from pre-synaptic cells in the basal ganglia and the frontal cortex. Such evidence strongly implicates the dopamine system in individual differences in this behaviour.

Further developments in the understanding of the biological basis for the condition have come from genetic studies. Using twins it has been shown that individual differences in the genetic makeup of children contribute substantially to the risk of hyperactivity (Goodman \& Stevenson, 1989). Subsequent molecular genetic studies have identified a number of genes that contribute to this genetic risk; in particular, genes acting on the dopamine system (for example, see Brookes et al. 2006). The effects on the levels of hyperactivity of any one of these genes is only modest, but there is now concerted evidence for the importance of their effect (Faraone et al. 2001).

Although genetic differences between children are important contributors to the level of hyperactivity, there are a wide range of other factors that can influence this behavioural pattern. For example, it has been shown that institutional rearing has a specific behavioural effect on the level of inattention and impulsivity in children. This relationship was first shown in a study of institutionalreared children in the UK (Tizard \& Hodges, 1978). More recently, longitudinal studies of children reared in 
Romanian orphanages under conditions of severe deprivation and adopted out of the country have shown increased levels of inattention and overactivity, as well as disturbances in attachment (Kreppner et al. 2001). Hyperactivity is also seen as the end point of a number of factors influencing early brain growth and development. For example, hypoxia has been found to specifically increase the rate of hyperactivity in children (Bass et al. 2004). Similarly, there is consistent evidence that prematurity is associated both with a lowering of the intelligence quotient and with a relatively specific behavioural change in terms of the risk of ADHD (Bhutta et al. 2002).

\section{Studies of diet and hyperactivity}

There are a number of ways in which dietary factors are thought to be related to hyperactivity, including the effects of specific dietary factors (fatty acids), allergy and food intolerance, and also the presence of artificial food colourings and flavourings. Each of these factors will be considered in turn.

Fatty acids. There have been repeated assertions that the level of $n-3$ fatty acids or the balance between $n-3$ and $n-6$ fatty acids are contributing factors to behavioural and cognitive development in children. The evidence from these studies is somewhat equivocal, with the best evidence arising from supplementation studies. However, the findings from supplementation studies are somewhat contradictory. In a study of children with ADHD (Stevens et al. 2003) essential fatty acid supplementation was not found to have an effect on hyperactivity. In contrast, in children with dyslexia reduced hyperactivity was observed, although there was no evidence of an effect on literacy (Richardson \& Puri, 2002). In children with developmental coordination disorder no benefit of supplementation on motor function was found (Richardson \& Montgomery, 2005). However, an improvement in the level of hyperactivity and of literacy was indicated. It would appear that there is some evidence that $n-3$ supplementation may improve the behaviour of some children, but perhaps only those who show specific learning disabilities. There is as yet no evidence of a beneficial effect in the general population of children.

Allergy and food intolerance. There have been a number of studies that have shown that, at least in some children, hyperactivity can be seen as a form of food intolerance (Egger et al. 1985; Carter et al. 1993). The first of these studies to provide convincing evidence was that of Egger et al. (1985), who investigated a sample of children ( $n$ 76) referred to Great Ormond Street Hospital, London, UK with the hyperkinetic syndrome, while often showing other neurological problems. A 'few-food' diet (an elimination diet that considers which foods are allowed rather than which foods should be avoided) was found to improve behaviour in a substantial proportion of the children. Subsequent food challenges were able to identify increases in hyperactivity in response to specific foods. This finding has been replicated by Carter et al. (1993) in a study in which a double-blind challenge protocol reintroducing foods was shown to produce a deterioration in behaviour and in psychological test performance. The importance of both studies is that they demonstrate that food can have a deleterious effect on hyperactivity, but in children with complex behavioural difficulties referred to specialist units. It is thus an open question as to whether these foodintolerance reactions are influential in increasing the levels of hyperactivity in a broader range of children.

Food additives. Feingold (1975) was one of the first to propose that food additives may be influencing the rates of hyperactivity in the population. He suggested that artificial food colours, flavourings and natural salicylates have a pharmacological effect, and advocated a diet that was free of these substances and would act as a treatment for, and prevention of, hyperactivity. A number of studies were subsequently conducted on the efficacy of this diet and a review from the National Advisory Committee on Hyperkinesis and Food Additives (1980) has concluded that there is no consistent evidence of a beneficial effect.

Subsequently, a number of further studies have been conducted on the effects of additives, but not necessarily using the full Feingold (1975) diet, and this literature has been reviewed by Schab \& Trinh (2004). Evidence was examined from fifteen double-blind placebo-controlled trials that had evaluated the behavioural effect of artificial food colourings in children who had been diagnosed as hyperactive, and using meta-analysis a significant effect of additives (effect size 0.283 (95\% CI 0.079, 0.488)) was demonstrated. Furthermore, in a secondary analysis of the effect of artificial food colours in eight trials involving children who did not necessarily have the hyperactive diagnosis the effect size was found to be somewhat lower at $0 \cdot 117(95 \%$ CI $0 \cdot 113,0 \cdot 347)$. There is therefore concerted evidence that dietary manipulations to remove artificial food colourings and flavourings can beneficially improve the behaviour of children with hyperactivity. However, it should be noted that in the fifteen trials reviewed by Schab \& Trinh (2004) a total of only 219 children had hyperactivity. The effects appear to be less substantial for the general population, and indeed in this meta-analysis the effect size was not significant.

A recently published UK study based on a general population of children (277 3-year-olds living in the Isle of Wight; Bateman et al. 2004), was designed to screen the general population for the presence of atopy and hyperactivity, and to identify four balanced groups of children with and without these two conditions. Atopy was identified on the basis of skin-prick testing and hyperactivity by using parental report. After an initial baseline assessment the children were placed for 1 week on an elimination diet to remove artificial colourings and benzoate preservatives. They then continued with this diet during a doubleblind crossover trial of a dietary challenge with a drink containing artificial colourings and sodium benzoate or a placebo mixture. Changes in the children's behaviour were monitored both by a tester who was blind to the child's dietary status week-by-week and by parents who were similarly blind to the challenge being given at any one time and made ratings of the child's behaviour.

Reductions in hyperactivity were observed during the introduction of the elimination diet. During the challenge weeks an increase in hyperactivity was found that was greater during the active periods than the placebo periods, 
based on parental ratings. The difference between the active and placebo periods could not be confirmed by testing of the child's behaviour in the clinic setting. It was interesting that the extent of the child's sensitivity to the effects of artificial food colourings and preservatives was not affected by their previous levels of hyperactivity or atopy. The study concludes that there is a general adverse effect of artificial colouring and benzoate preservatives on the behaviour of 3-year-old children that is detectable by parents but not by clinic assessment. A similar pattern of behavioural change that can be detected by parental rating but not in the clinic setting has been reported (ShulteKorne et al. 1996) in an investigation of the influence of an oligoantigenic diet on twenty-one children with a diagnosis of ADHD.

A secondary analysis to identify the characteristics of the Isle of Wight children showing greater behavioural change in response to artificial food colourings (Bateman et al. 2004) has failed to identify any particular subgroup as being more affected. In this analysis a broad range of social and demographic and family background factors were examined. Although some children were found to react to additives more than others, the study was unable to identify any distinctive characteristics of responders. The most parsimonious explanation of the findings is, therefore, that the effects simply represent extremes on a range of reaction.

The Isle of Wight study (Bateman et al. 2004) has presented findings that are suggestive of a possible public health benefit to the removal of food colourings and benzoate preservatives from the diet of young children. However, the results are somewhat equivocal, as they only relate to the parent ratings. Although in many ways the ecological validity of parental assessments of behaviour is high, it would be preferable if they could be supported by observations by independent observers or by the use of standardised tests.

A study that was designed to replicate and extend the Isle of Wight findings and included both 3-year-old and 8 -year-old children has been undertaken. Again, doubleblind food challenges were used, but in this trial two separate mixes of additives were tested. One additive mix replicated the mix used by Bateman et al. (2004) and the second mix reflected a more representative range of contemporary additives in children's food. In addition to parental ratings of behaviour, information was obtained from direct observation of the children's behaviour in nursery classes and school classes, and from teacher ratings of behaviour. In addition, for the older sample the continuous performance test was used as a measure of attention (Conners, 1992). One addition to this current study was the genotyping of the children to identify whether genes involved in the dopamine system may moderate the impacts of additives. This study has now been completed, and results will available in mid-2007.

\section{Conclusions}

There is a multiplicity of ways in which food and diet can affect cognition and behaviour in children. Some of these effects appear to be weak, e.g. in terms of the type of diet and its impact on behaviour. Other effects are strong but are only seen at the extremes, e.g. the impact of malnutrition. Other dietary effects may be limited to exceptional subgroups, e.g. the impact of $n-3$ fatty acid supplementation has to date only been convincingly demonstrated with children with types of specific learning disability. Other dietary effects may hold across the population. At present, there appears to be a strong possibility that food additives are having a pervasive effect across the population of children to increase the rates of hyperactivity.

In relation to hyperactivity, it is clear that food is only one of a number of influences of individual differences in this behavioural pattern; other factors include brain damage associated with prematurity and institutional rearing. It is also known that genetic differences affect children, and it is an open question as to whether some of the effects of genes are the result of a modification of a reaction to food leading to an intolerance of additives. The importance of the possible effect of additives is that it is a factor that contributes to the risk of increasing the level of hyperactivity in young children. Early hyperactivity is a risk factor for later ADHD, educational difficulties and conduct disorder (Taylor et al. 1996). It is possible for artificial food colourings, flavourings and preservatives to be removed from children's food and the public health benefits of such an action may be considerable.

\section{References}

Bass JL, Corwin M, Gozal D, Moore C, Nishida H, Parker S, Schonwald A, Wilker RE, Stehle S \& Cinane TB (2004) The effect of chronic or intermittent hypoxia on cognition in childhood: A review of the evidence. Paediatrics 114, 805-816.

Bateman B, Warner JO, Hutchinson E, Dean T, Rowlandson P, Gant C, Grundy J, Fitzgerald C \& Stevenson J (2004) The effects of a double blind, placebo controlled, artificial food colourings and benzoate preservative challenge on hyperactivity in a general population sample of pre-school children. Archives of Disease in Childhood 89, 506-511.

Bellisle F (2004) Effects of diet on behaviour and cognition in children. British Journal of Nutrition 92, Suppl. 2, S227-S232.

Berkman DS, Lescano AG, Gilman RH, Lopez S \& Black MM (2002) Effects of stunting, diarrhoeal disease and parasitic infection during infancy on cognition in late childhood: A follow-up study. Lancet 359, 364-371.

Bhutta AT, Cleves MA, Casey PH, Cradock MM \& Anand KJS (2002) Cognitive and behavioural outcomes of school aged children who were born pre-term - A meta-analysis. Journal of the American Medical Association 288, 728-737.

Boys A, Farrell M, Taylor C, Marsden J, Goodman R, Brugha T, Bebbington P, Jenkins R \& Meltzer H (2003) Psychiatric morbidity and substance use in young people aged 13 to 15 years: Results from the Child and Adolescent Survey of Mental Health. British Journal of Psychiatry 182, 509-517.

Brookes KJ, Mill J, Guindalini C, Curran S, Xu XH, Knight J et al. (2006) A common haplotype of the dopamine transporter gene associated with attention-deficit/hyperactivity disorder and interacting with maternal use of alcohol. Archives of General Psychiatry 63, 74-81.

Carter CM, Urbanowicz M, Hemsley R, Mantilla L, Strobel S, Graham PJ \& Tayor E (1993) Effects of a few food diet on Attention Deficit Disorder. Archives of Disease in Childhood 69, 564-568. 
Chang SM, Walker SP, Grantham-McGregor S \& Powell CA (2002) Early childhood stunting and later behaviour and school achievement. Journal of Child Psychology and Psychiatry 43, 775-783.

Conners CK (1992) Manual for the Conners Continuous Performance Task. Toronto, Ont.: Multi-Health Systems.

Egger J, Graham PJ, Carter CM, Gumley D \& Soothill JF (1985) Controlled trial of oligo antinergenic treatment in hyper kinetic syndrome. Lancet i, 540-545.

Faraone SB, Doyle AE, Mick E \& Biederman J (2001) Metaanalysis of the association between the 7 repeat allele of the dopamine $\mathrm{d} 4$ receptor gene and Attention-Deficit Hyperactivity Disorder. American Journal of Psychiatry 158, 1052-1057.

Feingold BF (1975) Hyperkinesis and learning disabilities linked to artificial food flavors and colors. American Journal of Nursing 75, 797-803.

Gibson EL \& Green MW (2002) Nutritional influences on cognitive function: Mechanisms of susceptibility. Nutrition Research Reviews 15, 169-206.

Goodman R \& Stevenson J (1989) A twin study of hyperactivity number 2: The aetiological role of genes, family factors and perinatal adversity. Journal of Child Psychology and Psychiatry 30, 691-709.

Kreppner JM, O'Connor TG \& Rutter M (2001) Can inattentions/ overactivity be an institutional deprivation syndrome? Journal of Abnormal Child Psychology 29, 513-528.

Morris N \& Sarll P (2001) Drinking glucose improves listening span in students who miss breakfast. Educational Research 43, 201-207.

National Advisory Committee on Hyperkinesis and Food Additives (1980) Final Report to the Nutrition Foundation. New York: Nutrition Foundation.

Richardson AJ \& Montgomery P (2005) The Oxford-Durham study: A randomised controlled trial of dietary supplementation with fatty acids in children with developmental coordination disorder. Paediatrics 115, 1360-1366.

Richardson AJ \& Puri BK (2002) A randomised double blind placebo controlled study of the effects of supplementation with highly unsaturated fatty acids on ADHD-related symptoms in children with specific learning difficulties. Progress in Neuro Psychopharmacology and Biological Psychiatry 26, 233-239.

Schab DW \& Trinh NHT (2004) Do artificial food colours promote hyperactivity in children with hyperactive syndromes? A meta-analysis of double blind placebo controlled trials. Journal of Developmental and Behavioural Paediatrics 25, 423-434.

Schulte-Korne G, Deimel W, Gutenbrumner C, Hennighausen K, Blank R, Rieger C \& Remschmidt H (1996) Der Einfluss einer oligoantigenen Diät auf das Verhalten von hyperkinetischen Kindern (The influence of an oligoantigenic diet on the behaviour of children with Attention-Deficit Hyperactivity Disorders). Zeitschrift für Kinder- und Jugendpsychiatrie und Psychotherapie 24, 176-183.

Sonuga-Barke EJS (2003) The dual pathway model of AD/HD: an elaboration of neuro-developmental characteristics. Neuroscience and Biobehavioral Reviews 27, 593-604.

Stevens L, Zhang W, Peck L, Kuczek T, Grevstad N, Mahon A, Zentall SS, Arnold IE \& Burgess JR (2003) EFA supplementation in children with attention, hyperactivity and other disruptive behaviours. Lipids 38, 1007-1021.

Taylor E, Chadwick O, Heptinstall E \& Danckaerts M (1996) Hyperactivity and conduct problems as risk factors for adolescent development. Journal of the American Academy of Child and Adolescent Psychiatry 35, 1213-1226.

Tizard B \& Hodges J (1978) The effect of early institutional rearing on development of 8 year old children. Journal of Child Psychology and Psychiatry 19, 99-118.

Walker SP, Chang SM, Powell CA \& Grantham-McGregor SM (2005) Effects of early childhood psychosocial stimulation and nutritional supplementation on cognition and education in growth stunted Jamaican children: Prospective cohort study. Lancet 366, 1804-1807.

Warner JO, Bateman BJ \& Stevenson J (2003) Behaviour and adverse food reactions. In Food Allergy: Adverse Reactions to Food and Food Allergies, pp. 522-531 [DD Metcalfe, HA Sampson and RA Simon, editors]. Oxford: Blackwell. 